\title{
Teaching Methods for Entrepreneurship Courses for Students in Taiwan
}

\author{
Lung-Tan Lu
}

\section{ABSTRACT}

This short research article aims to present the teaching entrepreneurial management for undergraduate students in Taiwan with higher power distance and uncertainty avoidance. Teachers and students have to keep distances and wear masks to avoid infection. However, it reduces the passionate of students to communicate and answer questions. Mobile App such as ZUVIO can help teachers and students to cope the situations. Teachers and students in Taiwan with higher power distance and higher uncertainty avoidance prefer to present lectures and ask students to memorize knowledge form textbooks. However, the kinds of teaching methods do not fit entrepreneurship courses, which require creativity and innovation. We used teamwork, project writing, and competition assessment to inspire their creativity and innovation, in order to reduce uncertainty avoidance. Moreover, we use online education software, ZUVIO, for students to vote on the project anonymously with the intention of decreasing power distance. Studies carried out at one university in Taiwan in 2018. Our sample came from around 50 students attended an entrepreneurship course in a university in Taiwan. At the end of the semester, students, mostly from China, Taiwan, Malaysia and Indonesia, students present innovative projects, attend competitions, and receive brilliant awards. We recommend teachers in Asian countries with higher power distance and higher uncertainty avoidance revise teaching methods according to their teaching situation. For instance, most business school teachers use paper-and-pencil tests to assess learning outcomes, but a small number of teachers competition to evaluate performance. It could cause a conflict situation between teachers.

Keywords: experiential learning, innovation, power distance, uncertainty avoidance

\section{INTRODUCTION}

The aims of this article are to present the teaching entrepreneurial management for undergraduate students in Taiwan with higher power distance and uncertainty avoidance. Traditionally, teaching in Taiwan entails presenting lectures to explain knowledge in textbooks. Students are used to take notes quietly during lectures. In the final examination, usually a paper-and-pencil test, the teacher asks questions, and students write down answers, which they memorize from textbooks. Teachers give them scores according to their attendance rate, assignments or mid-term reports, along with their answers in the final examination. However, can these students learn real business-world skills by memorizing knowledge form textbooks? How can we make the business classroom similar to the real business world?

Cultural differences across national boundaries have been considered as one of the most challenges in higher education $[1,2]$. In the famous IBM survey, Hofstede defines culture as 'the collective programming of the mind which distinguish members of one human group from another' (1980, p.25). He
Published Online: March 29, 2021

ISSN: $2736-4534$

DOI :10.24018/ejedu.2021.2.2.73

Lung-Tan Lu*

Fo Guang University, Taiwan

(e-mail: 1tlu@mail.fgu.edu.tw) clustered national culture as four dimensions:

1) power distance

2) individualism

3) uncertainty avoidance

4) masculinity

Power distance (PD) refers to the fact that all human beings in societies are not equal. Individualism (IDV) refers to the relationship between individuals and the collectivities, which prevails in a given society $[3,4,5]$. China and Taiwan both are high power distance and low individualism nations, studies confirmed cultural differences have impact on Chinese learners in USA and China [6,7].

In the era of COVID-19, teachers and students have to keep distances and wear masks to avoid infection. However, it reduces the passionate of students to communicate and answer questions. Mobile App such as ZUVIO can help teachers and students to cope the situations. A review of teaching methods for entrepreneurship courses discloses a range of ways to teach, such as case study, team-based learning, one business idea for all students, poster plan, presentation sessions, and so on [8]. However, the literature offers indefinite guidelines or frameworks for selecting specific teaching methods for students from various cultural 
backgrounds. Entrepreneurship courses require students to be innovative and take risks. With the aim of accomplishing these goals, we decide to apply several teaching methods:

1) team-based learning

2) project orientation

3) peer rating

4) competition assessment

5) online education software [9].

\section{METHODOLOGY}

Our sample came from around 50 students attended an entrepreneurship course in a university in Taiwan. In our entrepreneurial management course, we ask undergraduate students to form teams. Each team has to write a business plan with improved product to participate in competitions. The first task is to ask all team members to describe one kind of merchandise in a field ( 1 to 6 ), in which they are unsatisfied with its functions. For example, bicycle seats (field 4) are not comfortable for long-distance riding (see Table 1). Finally, the students have to create an illustration of improved merchandise and label each part. There are three steps of tasks: (1) Task one: Each member describes one kind of merchandise in a field (1 to 6), whose function they are unsatisfied with. For example, bicycle seats (field 4) are not comfortable for long-distance riding; (2) Task two: Describe how to improve its functions; (3) Task three: Create an illustration of the improved merchandise and label each part.

TABLE I: CREATIVE THINKING

\begin{tabular}{llllll}
\hline \hline Team member & A & B & C & D & E \\
\hline 1. Food & & & & & \\
2. Clothing & & & & & \\
3. Housing & & & & & \\
4. Transport & & & & & \\
5. Education & & & & & \\
6. Entertainment
\end{tabular}

TABLE II: PEER RATING

\begin{tabular}{ll}
\hline \hline Questions & \multicolumn{1}{c}{ Contents } \\
\hline Question 1 & $\begin{array}{l}\text { According to the presentation, are modern users } \\
\text { unsatisfied with the former merchandise's functions? }\end{array}$ \\
Question 2 & $\begin{array}{l}\text { Do they think the improvement plan can address the } \\
\text { former merchandise's disadvantage? } \\
\text { If they were the former merchandise's users, would } \\
\text { they spend a little bit more money to buy the improved } \\
\text { one? }\end{array}$ \\
\hline \hline
\end{tabular}

\section{RESULTS AND DISCUSSION}

The following week, all team leaders need to integrate members' opinions to determine which improved item will represent their team to present in front of all students in the course. How can they decide these ideas are good enough to write a business plan to participate in competitions? Traditionally, the teacher makes the decision in higher power distance countries. However, we use an online program called "ZUVIO" to complete the peer rating, in which all students can present their opinion anonymously. First question of exercise one in the ZUVIO, according to the presentation, are modern users unsatisfied with the former merchandise's functions? Second question, do they think the improvement plan can address the former merchandise's disadvantage? Final question, if they were the former merchandise's users; would they spend a little bit more money to buy the improved one (see Table 2). A team can enter the next stage to write a business plan when the three tasks receive more than $50 \%$ of the classmates' approvals. Students are motivated to seek their peers' recognition rather than follow the teacher's orders.

After completing the business plan, it's time to win competitions. We also change the evaluation method. This course does not have a final examination consisting of a paper-and-pencil test. All teams are guaranteed an A if they are one of the top 3 in on of the entrepreneur competitions. Others can obtain a B or C with their assessments. In the end, three of eight teams won a top 3 ranking and earned an $\mathrm{A}$. four teams earned a B and one team earned a C. Some of the improvement plans have potential for a patent application. We help them apply for an approved patent in Taiwan [10].

\section{CONCLUSION}

It is quite difficult for teachers to motivate students with creativity and innovation in Asian countries with higher power distance and uncertainty avoidance. Because most students have been trained to listen to teachers' lectures and memorize knowledge in textbooks since primary school, it is quite difficult for them to include something new, something special in their business plans. We use several teaching methods: team-based learning, project orientation, peer rating, competition assessment, and online education software, to motivate these students and encourage significant changes in their business plans. One can download the ZUVIO app from Android Play or Apple Store, or use a PC to access its website. I provided a ZUVIO user name and password, to access this ZUVIO course, entrepreneurial management. We would like to suggest English users to utilize Google Translator because the ZUVIO website is in Chinese, but the questions in the entrepreneurial management course are in English. We recommend teachers in Asian countries with higher power distance and higher uncertainty avoidance revise teaching methods according to their teaching situation

Some of our teaching methods are inspired by the book, Teaching Entrepreneurship: A Prctice-Base Approach, [11]. We recommend teachers in Asian countries with higher power distance and higher uncertainty avoidance revise teaching methods according to their teaching situation. For instance, most business school teachers use paper-and-pencil tests to assess learning outcomes, but a small number of teachers competition to evaluate performance. It could cause a conflict situation between teachers.

\section{ACKNOWLEDGMENT}

The early version of this short research article was presented at the 2019 AIB Meeting in Copenhagen; the author thanks reviewers and Professor $\mathrm{Su}$ for their valuable comments. 


\section{REFERENCES}

[1] L. Lu, C. L. Cooper, S. F. Kao, Y. Zhou, "Work stress, control beliefs and well-being in Greater China: an exploration of sub-cultural differences between the PRC and Taiwan," Journal of Managerial Psychology, vol.18, no.6, pp. 479-510, Sep. 2003.

[2] L. Lu, "The Impact of Culture and Conflict Resolution Strategy on Role Stress in Asia", Journal of Advanced Management Science, vol.3, no.2, pp. 139-146, Mar. 2015.

[3] G. Hofstede, Culture's Consequences. CA, USA: SAGE Publishing, 1980, ch.1.

[4] G. Hofstede, "The Cultural Relativity of Organizational Practices and Theories", Journal of International Business Studies, vol.14, no.2, pp. 75-89, Apr. 1983.

[5] G. Hofstede, Culture and Organizations: Software of the mind. London, UK: McGraw-Hill, 1991, ch.3.

[6] X. Yang, "The Cultural Factors in the MOOC Design in China from Hofstede's Cultural Dimensions", Theory and Practices in Language Studies, vol.9, no.10, pp. 1320-1325, Oct. 2019.

[7] Y. Zhang, "Power Distance in Online Learning: Experience of Chinese Learners in U.S. Higher Education", The International Review of Research in Open and Distributed Learning, vol.14, no.4, pp. 238-254, Aug. 2013.

[8] P. Balan, "Metcalfe M. Identifying teaching methods that engage entrepreneurship students", Education + Training, vol.54. no.5, pp. 368-384, Jun, 2012.

[9] P. Blenker, S. Elmholdt, S. Frederiksen, S. Korsgaard, K. Wagner, "Methods in entrepreneurship education research: a review and integrative framework," Education+Training, 2014; vol.56, no.8, pp. 697-715, Aug, 2014.

[10] L. Lu, S. Cheng, "A STRUCTURE OF DETACHED BICYCLE SEAT," Taiwan Patent M571821, Dec. 21, 2018.

[11] H. Neck, P. Green, C. Brush, Teaching Entrepreneurship: A PracticeBase Approach. London, UK: Edward Elgar Publishing, 2014, ch.5.

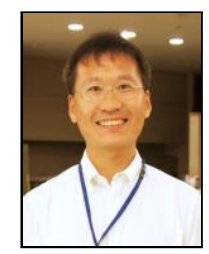

Lung-Tan Lu is an Associate Professor at the Department of Management, Management School, Fo Guang University, Taiwan.

He received his MBA degree from Chinese Culture University, Taiwan. His doctoral degree in International Business obtained from Business School, Leeds University, UK. Dr. Lu has been published two books and thirty referred papers. 